
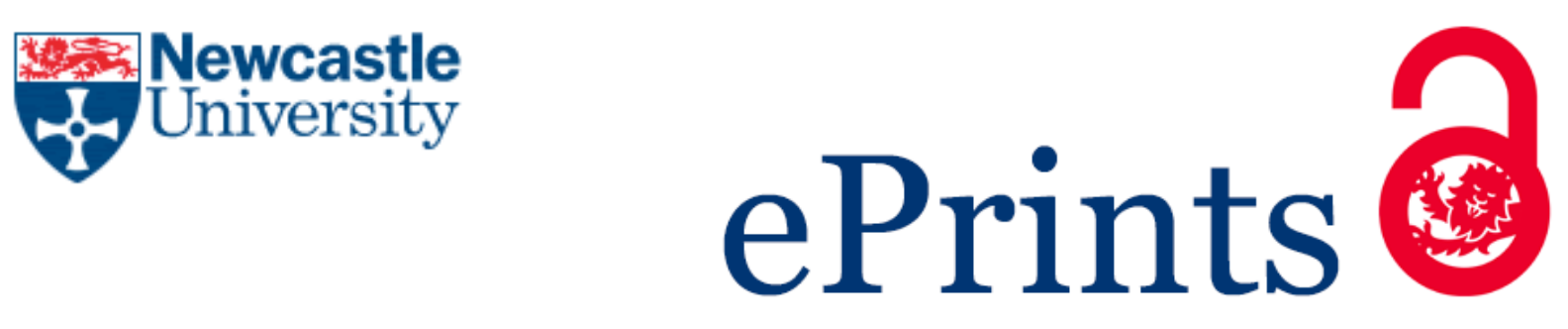

Radwan M, Wilkinson DJ, Hui W, Destrument AP, Charlton SH, Barter MJ, Gibson B, Coulombe J, Gray DA, Rowan AD, Young DA. Protection against murine osteoarthritis by inhibition of the 265 proteasome and lysine-48 linked ubiquitination. Annals of the Rheumatic Diseases 2014.

\title{
Copyright:
}

(C) Copyright Article author (or their employer) 2014. Produced by BMJ Publishing Group Ltd (\& EULAR) under licence.

DOI link to article:

http://dx.doi.org/10.1136/annrheumdis-2013-204962

Date deposited:

$25 / 06 / 2015$

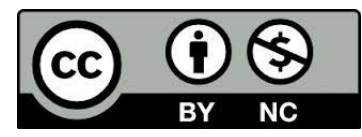

This work is licensed under a Creative Commons Attribution-NonCommercial 3.0 Unported License 


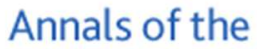 \\ RHEUMATIC DISEASES \\ The Eular Journal}

\section{Protection against murine osteoarthritis by inhibition of the 265 proteasome and lysine-48 linked ubiquitination}

\begin{tabular}{|c|c|}
\hline Journal: & Annals of the Rheumatic Diseases \\
\hline Manuscript ID: & annrheumdis-2013-204962.R1 \\
\hline Article Type: & Extended report \\
\hline Date Submitted by the Author: & $\mathrm{n} / \mathrm{a}$ \\
\hline Complete List of Authors: & $\begin{array}{l}\text { Radwan, Marta; Newcastle University, Musculoskeletal Research Group, } \\
\text { Institute of Cellular Medicine } \\
\text { Wilkinson, David; Newcastle University, Musculoskeletal Research Group, } \\
\text { Institute of Cellular Medicine } \\
\text { Hui, Wang; Newcastle University, Musculoskeletal Research Group, } \\
\text { Institute of Cellular Medicine } \\
\text { Destrument, Auriane; Newcastle University, Musculoskeletal Research } \\
\text { Group, Institute of Cellular Medicine } \\
\text { Charlton, Sarah; Newcastle University, Musculoskeletal Research Group, } \\
\text { Institute of Cellular Medicine } \\
\text { Barter, Matt; Newcastle University, Musculoskeletal Research Group, } \\
\text { Institute of Cellular Medicine } \\
\text { Gibson, Beth; Newcastle University, Musculoskeletal Research Group, } \\
\text { Institute of Cellular Medicine } \\
\text { Coulombe, Josee; Ottawa Hospital Research Institute, Centre for Cancer } \\
\text { Therapeutics } \\
\text { Gray, Douglas; Newcastle University, Musculoskeletal Research Group, } \\
\text { Institute of Cellular Medicine; Ottawa Hospital Research Institute, Centre } \\
\text { for Cancer Therapeutics } \\
\text { Rowan, Andrew; Newcastle University, Musculoskeletal Research Group, } \\
\text { Institute of Cellular Medicine } \\
\text { Young, David; Newcastle University, Musculoskeletal Research Group, } \\
\text { Institute of Cellular Medicine }\end{array}$ \\
\hline Keywords: & Osteoarthritis, Chondrocytes, Cytokines \\
\hline
\end{tabular}

\section{SCHOLARONE ${ }^{m}$ \\ Manuscripts}


Running head: ubiquitination in osteoarthritis

Protection against murine osteoarthritis by inhibition of the $26 \mathrm{~S}$ proteasome and lysine-48 linked ubiquitination

Marta Radwan ${ }^{1,2}$, David J. Wilkinson ${ }^{1}$, Wang Hui ${ }^{1}$, Auriane P. M. Destrument ${ }^{1}$, Sarah H. Charlton ${ }^{1}$, Matt J. Barter ${ }^{1}$, Beth Gibson ${ }^{1}$, Josée Coulombe ${ }^{3}$, Douglas A. Gray ${ }^{1,3 \pm}$, Andrew D. Rowan $^{1}$ and David A. Young ${ }^{1 *}$

${ }^{1}$ Musculoskeletal Research Group, Institute of Cellular Medicine, Medical School, Newcastle University, Newcastle-upon-Tyne, NE2 4HH,UK

${ }^{2}$ current address: Cardiff School of Biosciences, The Sir Martin Evans Building, Cardiff University, Cardiff, CF10 3AX, UK

${ }^{3}$ Centre for Cancer Therapeutics, Ottawa Hospital Research Institute, Ottawa, Ontario, Canada K1H 8 L6 ( \pm current address)

*Address correspondence to: David A. Young, PhD; Musculoskeletal Research Group, Institute of Cellular Medicine, $4^{\text {th }}$ Floor Cookson Building, Medical School, Newcastle University, Newcastle upon Tyne, NE2 4HH, UK Tel +44 191 2223850, Fax +44 191 2225455;

E-mail: david.young@ncl.ac.uk

\section{Licence for Publication}

The Corresponding Author has the right to grant on behalf of all authors and does grant on behalf of all authors, an exclusive licence (or non exclusive for government employees) on a worldwide basis to the BMJ Publishing Group Ltd to permit this article (if accepted) to be published in ARD and any other BMJPGL products and sublicences such use and exploit all subsidiary rights, as set out in our licence (http://group.bmj.com/products/journals/instructions-for-authors/licence-forms).

Competing Interest: None declared.

Running head: ubiquitination in osteoarthritis

Word count: 3445 
Running head: ubiquitination in osteoarthritis

\section{ABSTRACT}

Objectives: To determine whether the process of ubiquitination and/or activity of the $26 \mathrm{~S}$ proteasome are involved in the induction of osteoarthritis (OA).

Methods: Bovine cartilage resorption assays, chondrocyte cell-line SW1353 and primary human articular chondrocytes were used with the general proteasome inhibitor MG132 or vehicle to identify a role of the ubiquitin-proteasome system (UPS) in cartilage destruction and matrix metalloproteinase-13 (MMP13) expression. In vivo, MG132 or vehicle, were delivered subcutaneously to mice following destabilisation of the medial meniscus (DMM) induced OA. Subsequently, DMM was induced in Lys-to-Arg (K48R and K63R) mutant ubiquitin (Ub) transgenic mice. Cytokine-signalling in SW1353s was monitored by immunoblotting and novel ubiquitinated substrates identified using Tandem Ubiquitin Binding Entities purification followed by mass spectrometry. The ubiquitination of TRAFD1 was assessed via immunoprecipitation and immunoblotting and its role in cytokine signaltransduction determined using RNA interference and real-time RT-PCR for MMP13 and interleukin-6 (IL6).

Results: Supplementation with the proteasome inhibitor MG132 protected cartilage from both cytokine-mediated resorption and degradation in vivo in mice following DMM-induced OA. Using transgenic animals only K48R-mutated Ub partially protected against OA compared to wild-type or wild-type Ub transgenic mice and this was only evident on the medial femoral condyle. After confirming ubiquitination was vital for NF- $\kappa B$ signalling and MMP13 expression, a screen for novel ubiquitinated substrates involved in cytokinesignalling identified TRAFD1; the depletion of which reduced inflammatory mediatorinduced MMP13 and IL6 expression.

Conclusions: Our data for the first time identifies a role for ubiquitination and the proteasome in the induction of $\mathrm{OA}$ via regulation of inflammatory mediator-induced MMP13 expression. These data open avenues of research to determine whether the proteasome, or K48-linked ubiquitination, are potential therapeutic targets in OA.

\section{Keywords}

Ubiquitin, proteasome, osteoarthritis, animal model, MMP13 
Running head: ubiquitination in osteoarthritis

\section{INTRODUCTION}

Osteoarthritis (OA) is the most prevalent joint disease,[1] the typifying feature of which is the progressive degradation of articular cartilage.[2] Cartilage itself is composed of an extracellular matrix (ECM) rich in proteoglycan (principally aggrecan) and collagen (mainly type II) maintained by the sole cell type, the chondrocyte. Remodelling and turnover of this ECM in normal physiology is mediated through the regulation of the expression of matrix components and matrix-degrading enzymes, the metalloproteinases.[3] The phenotype of the chondrocytes shifts in $\mathrm{OA}$, through as yet unidentified processes, to favour catabolism with an increase in metalloproteinase expression evident. Matrix metalloproteinase (MMP)13 is the generally accepted type II collagen-degrading proteinase in OA with pathological aggrecan cleavage mediated by ADAMTS enzymes, most probably ADAMTS-5.[4] Mechanisms to alter the expression of these enzymes in $\mathrm{OA}$ are potential therapeutic targets in what is currently a disease only treatable by joint replacement surgery.

Cellular proteins exist in a dynamic state with multiple pathways leading to their degradation, the best characterised being the ubiquitin-proteasome system (UPS). The UPS plays a pivotal role in the degradation of proteins important in numerous cellular processes including signal transduction pathways, a notable example being that of the NF- $\kappa B$ pathway via the regulation of $I \kappa B$ degradation. I $\mathrm{K} B$ s normally bind and sequester NF- $\kappa B$ dimers in the cytoplasm, but following their degradation the NF-KB complex translocates to the nucleus and regulates inflammatory signalling. Like most proteins destined for degradation via the UPS, IKB is covalently modified by the attachment of the small polypeptide ubiquitin (Ub). Subsequently, additional Ub polypeptides can be covalently attached to the first Ub to create a poly-Ub chain that eventually directs the client protein for proteasomal degradation. $[5,6]$

Ub itself is a highly-conserved 76 amino acid polypeptide expressed by all eukaryotes. The covalent attachment of Ub to cellular proteins, ubiquitination, occurs at lysine (K) residues. Ub itself contains seven $K$ residues which allows for different poly-Ub chains to be generated including $\mathrm{K} 48$ chains which target proteins to the proteasome. K63 and linear Ub 
Running head: ubiquitination in osteoarthritis

chains have emerged as having important roles in signal transduction pathways, the most studied again being the NF-אB pathway.[6]

The aim of this study was to investigate the role of Ub and the UPS in the induction of OA in a murine model and to identify novel targets of $\mathrm{Ub}$, all of which may have potential therapeutic relevance. 
Running head: ubiquitination in osteoarthritis

\section{METHODS}

\section{Cells, samples and treatments}

This study was performed with Ethical Committee approval from the Newcastle and North Tyneside Health Authority, UK. Human articular chondrocytes (HACs) were from consenting patients undergoing knee joint replacement surgery and were isolated and cultured as described.[7] Human chondrosarcoma cells (SW1353) were cultured as described.[8] Cells were seeded one day before treatment and cultured in serum-free medium overnight prior to stimulation. Cells were stimulated with human recombinant $\mathrm{IL}-1 \alpha(0.5 \mathrm{ng} / \mathrm{ml})$ or 0.5 $\mu \mathrm{g} / \mathrm{ml}$ poly(I-C) (Invivogen, Source BioScience LifeSciences, Nottingham, UK). Where indicated, cells were treated $1 \mathrm{~h}$ before and during stimulation with MG132 $(5 \mu \mathrm{g} / \mathrm{ml}$ ) (Tocris biosciences, R\&D Europe Ltd. Abingdon, UK or Sigma-Aldrich Ltd. Poole, UK).

\section{Gene depletion/RNA intereference (RNAi)}

Cells were transfected with siRNA ( $50 \mathrm{nM}$ ) for $48 \mathrm{~h}$ using Dharmafect 1 (Dharmacon, Thermo Fisher Scientific, Epsom, UK) according to the manufacturer's protocol and as described previously. $[7,8]$ The following siRNAs were used: siGENOME SMARTpool: siGenome TRAFD1 siRNA (M-004097-01-0005) and siGenome Non-targeting siRNA pool \#2 (D-001206-1420)(siCon)(Dharmacon).

\section{Immunoblotting}

Whole cell lysates were prepared as described but supplemented with $20 \mathrm{mM} \mathrm{N}$ ethylmaleimide, to block deubiquitination.[7] Protein extracts were separated by SDS-PAGE, transferred to PVDF or nitrocellulose membranes and probed with the following antibodies: anti-IKB $\alpha$; anti-phospho-NF-KB p65; anti-FLAG (Cell Signaling, New England Biolabs (UK) Ltd, Hitchin, UK); anti-GAPDH (Chemicon, Millipore (U.K.) Ltd., Watford, UK); anti-TRAFD1 (Santa Cruz Biotechnology (SCBT), Inc., Insight Biotechnology Ltd., Wembley, UK), and antiUbiquitin (Dako UK Ltd, Ely, UK).

\section{Enrichment of proteins with Tandem Ubiquitin Binding Entities (TUBES)}

SW1353 protein extracts were prepared following $30 \mathrm{~min}$ stimulation with IL-1, $1 \mathrm{~h}$ stimulation with poly $(\mathrm{I}-\mathrm{C})$, or under basal conditions, all in presence of MG132. Cell lysis 
Running head: ubiquitination in osteoarthritis

buffer (50 mM Tris- $\mathrm{HCl} \mathrm{pH}$ 7.5, $0.15 \mathrm{M} \mathrm{NaCl}, 1 \mathrm{mM}$ EDTA, 1\% NP40, 10\% glycerol) was supplemented with protease inhibitor cocktail (Sigma-Aldrich) and $20 \mathrm{mM} \mathrm{N}$ ethylmaleimide, and concentrated with a 9 kDa cut-off filter (Pierce, Thermo Fisher Scientific). $4.5 \mathrm{mg}$ of protein were pre-cleared with $50 \mu \mathrm{l} 50 \%$ slurry of control agarose for $30 \mathrm{~min}$, and then incubated with $200 \mu \mathrm{l}$ of 50\% slurry TUBE 2 (tebu-bio Ltd, Peterborough, UK) overnight at $4{ }^{\circ} \mathrm{C}$.[9] Enriched proteins were washed thrice with TBS-T (20 mM Tris- $\mathrm{HCl}$ $\mathrm{pH} 8.0,0.15-0.2 \mathrm{M} \mathrm{NaCl}, 0.1 \%$ Tween-20), eluted with $200 \mu \mathrm{l} 0.2 \mathrm{M}$ glycine- $\mathrm{HCl} \mathrm{pH} 2.5$ and concentrated with a $10 \mathrm{kDa}$ cut-off filter (Amicon, Millipore, Thermo Fisher Scientific, Epsom, UK). Enrichment of ubiquitinated polypeptides was visualised by immunoblotting prior to being reduced with $1 \mathrm{mM} \mathrm{DTT}$, alkylated with $5 \mathrm{mM}$ chloroacetamide, and trypsin (Promega, Southampton, UK) digested at $37^{\circ} \mathrm{C}$ overnight before identification by mass spectrometry (MS).

\section{Mass spectrometric analysis and data analysis}

MS was performed by Dundee Cell Products Ltd. (Dundee, UK) on an UltiMate ${ }^{\mathrm{TM}} 3000 \mathrm{nLC}$ (Thermo scientific) coupled to a LTQ Orbitrap XL (Thermo Scientific). RAW data files were extracted with Raw2MSM and searched using Mascot Search Engine. A maximum of 2 missing tryptic cleavages and the following modifications were selected for database search criteria: fixed modifications: Carbamidomethyl (C); variable modifications: Acetyl (N-term), Dioxidation (M), Gln->pyro-Glu (N-term Q), Oxidation (M), with/without GlyGly (K). The relative quantification of proteins (spectral count) was performed using an exponentially modified abundance index (emPAl) as described.[10]

\section{TRAFD1 cloning and immunoprecipitation}

A human TRAFD1 ORF clone, IRQMp5018H057D (Source Bioscience), was PCR amplified using primers 5'-CAGTGTGGTGGAATTTCGTCCCTGGAAGAGCTAAA-3' and 5'GATATCTGCAGAATTCTCCTCCTCTTCCTCTTCTGC $-3^{\prime}$ and subcloned into a modified pCDNA4 (Life Technologies, Paisley, UK) vector using In-Fusion (Takara Bio Europe/Clontech, SaintGermain-en-Laye, France) to create a C-terminal FLAG-tag fusion protein. SW1353s were transfected using JetPEI (Source Bioscience) and TRAFD1 expression detected by immunoblotting. Transfected cells were treated as indicated. Over-expressed TRAFD1 was immunoprecipitated from $150 \mu \mathrm{g}$ of whole-cell-lysate with $1.5 \mu \mathrm{g}$ of anti-FLAG antibody 
Running head: ubiquitination in osteoarthritis

(Sigma-Aldrich) overnight at $4^{\circ} \mathrm{C}$, then incubated with $20 \mu$ protein G PLUS-agarose (SCBT) for $1 \mathrm{~h}$ at $4^{\circ} \mathrm{C}$. Bound proteins were washed once with lysis buffer and twice with TBS-T and eluted with $50 \mu \mathrm{l} 2 \times$ Laemmli sample buffer prior to SDS-PAGE and immunoblotting with the anti-FLAG or anti-Ub (after autoclaving of membranes) antibodies.

\section{Real-time reverse transcription-PCR}

Total RNA from cells was extracted using Cells-to-cDNA II kit, RNAse-free DNAse (Life Technologies) treated, and cDNA synthesised as described.[11] Primers and probes were as published [7] or designed by the Universal Probe Library (Roche Applied Science, Burgess Hill, UK) and were: TRAFD1 F 5'-CAGCCTCAAGAGACCTCACC-3' and $\mathrm{R}$ 5'TCCAGGTAACCAGAAGACAGGT-3' with probe\#44; IL6 5'-GATGAGTACAAAAGTCCTGATCCA-3' and R 5'-CTGCAGCCACTGGTTCTGT-3' with probe\#40. Real-time RT-PCR performed and analysed as described.[12]

\section{In vitro cartilage degradation assay}

Cultured bovine cartilage discs were incubated with serum-free DMEM containing IL-1 (1 $\mathrm{ng} / \mathrm{ml})$ and Oncostatin M (OSM) (10 ng/ml) \pm DMSO/or MG132 $(5 \mu \mathrm{g} / \mathrm{ml})$ and refreshed on day 7. Residual cartilage explants were papain digested overnight at $65^{\circ} \mathrm{C}$. Hydroxyproline (OHPro) and glycosaminoglycan (GAG) release were assayed as described.[13] Conditioned media was assessed at day 7 and 14 (presented) for damaged cells using the Toxilight ${ }^{\mathrm{TM}}$ BioAssay Kit (Lonza, Slough, UK). Day 0 cartilage was freeze-thawed thrice as a positive control of cell damage.

\section{Experimental osteoarthritis}

Experiments were performed on wild-type C57BL/6J or mutant-Ub transgenic mice housed in standard cages with ad libitum food and water in accordance with UK Home Office regulations. OA was induced in 8 week old animals, following surgical sectioning of the medial meniscotibial ligament with sham operation as control (data not shown).[14] MG132 or vehicle (50\% DMSO/50\% polyethylene glycol 300) was delivered via osmotic mini-pump (1004; ALZET Osmotic Pumps, Cupertino, CA, USA) implanted subcutaneously and delivering $0.125 \mu \mathrm{l} / \mathrm{h}$. Based upon previous studies (e.g. [15]), a single concentration of MG132 (6.6 
Running head: ubiquitination in osteoarthritis

$\mathrm{mg} / \mathrm{ml}$ ) was selected which delivered $1 \mathrm{mg} / \mathrm{kg} /$ day (8 mice/group). Osmotic pumps were replaced after 4 weeks. 8 weeks post-surgery mice were euthanized and knee joints harvested for histological examination and scoring. On average 14 sections/joint, harvested at approximately $80 \mu \mathrm{m}$ intervals, were used for histological scoring by two blinded scorers.[16, 17] Averaged scores for the maximally affected sections are presented. Transgenic mutant-Ub animals were as described, $[18,19]$ where all three transgenic mouse lines express human $\mathrm{Ub}$ as a linear fusion with a $\mathrm{N}$-terminal $6 \times \mathrm{His}$ tag and a C-terminal enhanced green fluorescent protein (eGFP), the latter being cleaved to generate eGFP and His-tagged Ub. Since all Ub-transgenes have an N-terminal His-tag none can support linear poly-ubiquitination. $\mathrm{K} 48 \mathrm{R} \mathrm{Ub}$ and $\mathrm{K} 63 \mathrm{R}$ expressing mice also have impaired $\mathrm{K} 48$ and $\mathrm{K} 63$ poly-ubiquitination respectively. Genotyping of mice was via GFP visualisation [19] and PCR using Ub forward primer: 5'-CATGCAGATCTTCGTGAAGACCCTGACCGGCAAG-3' and GFP reverse primer: 5' CCTGCCGGTGGTGCAGAT-3' followed by restriction digestion with the endonuclease NgoMIV which only cleaves the K48R PCR amplicon.

\section{Statistical analysis}

All values are given as mean values of replicates with error bars representing the standard error of the mean (SEM). Mann-Whitney U-test was used to assess independent pairs with a Student's t-test used for real-time PCR data analysis using Graphpad Prism Software (GraphPad Software, Inc., La Jolla, USA), where * $p \leq 0.05, * * p \leq 0.01, * * * p \leq 0.001$. 
Running head: ubiquitination in osteoarthritis

\section{RESULTS}

Inhibition of the proteasome reduces cartilage destruction and MMP13 expression

MG132 reduces the degradation of ubiquitin-conjugated proteins by the $26 \mathrm{~S}$ proteasome complex and because this diverts ubiquitin pools into futile conjugates it has the effect of disrupting Ub homeostasis. Since poly-ubiquitination is strongly associated with NF-KB signal transduction,[20] we evaluated the effect of MG132 on cytokine-induced cartilage destruction using an established bovine cartilage model.[13] MG132 completely ameliorated the cartilage damage, as measured using glycosaminoglycan (GAG) and hydroxyproline (OHPro) release as surrogates for aggrecan and collagen destruction, mediated by the IL-1+OSM combination (Fig. 1A and B). Potential cytotoxicity of the MG132 treatment was assessed at day 7 and 14 (presented Fig. 1C) and showed low toxicity compared to freeze-thawed cartilage or the IL-1+OSM cytokine combination.

Cartilage-collagen turnover is mediated by MMPs, with MMP13 the accepted collagenase in OA. In both HAC and SW1353 cells, MG132 completely abolished the IL-1 or poly(I-C) (pIC) induced MMP13 expression, the latter stimulus being a double-stranded RNA mimic which is a potent inducer of MMP13 in HAC (Fig 1D).[7] Since IL-1 and poly(I-C) activate the NF-KB signalling pathway, we examined the effect of MG132 on the activation of this pathway by assessing the phosphorylation status of the NF- $\mathrm{KB}$ component $\mathrm{p} 65$ and the degradation of $I \kappa B \alpha$, which is a consequence of K48 poly-ubiquitination. Interestingly, MG132 caused an increase in P-p65 even under basal conditions, as has previously been reported.[21] Using an early time-point of stimulation (15 min), at which $I \kappa B \alpha$ degradation is initiating, $[7,8]$ we observed MG132 caused an increase in higher molecular weight $1 \kappa B \alpha$ immune-reactive products which we ascribed to be K48 poly-ubquitinated forms (Fig 1E).

\section{Inhibition of the proteasome reduces induced-OA in mice}

Given the ability of MG132 to protect against cytokine-induced cartilage destruction, we tested the efficacy of the compound in the murine DMM model of post-traumatic OA. MG132 was delivered systemically post-surgery for the eight week duration of the experiment at which point OA was assessed by histological scoring.[16] By this time-point in the model, cartilage lesions develop primarily on the central weight-bearing region of the 
Running head: ubiquitination in osteoarthritis

medial-tibial plateau and to a lesser extent the medial-femoral condyles.[14] MG132 significantly reduced cartilage damage in the most affected medial-tibial plateau but showed little evidence of efficacy for the less damaged femoral condyle (Fig. 2A and B). Summation of the medial-femoral and tibial histological scores demonstrated an overall protection of cartilage loss in MG132 administered animals (Fig. 2B). Similarly to other studies (e.g. [22]), the administration of MG132 at this dose and for this length of time had no effect on the activity/wellbeing of the mice and had no impact on the weight of the animals.

\section{K48 poly-ubiquitination plays a role in DMM-induced OA}

To determine the mechanism by which MG132 protected the mice from induced-OA, we performed DMM surgery on transgenic mice expressing one of three mutated forms of Ub, unable to form specific poly-Ub chains, in addition to their endogenous Ub genes.[18] When examining the medial tibial plateau none of the mutant-Ub mice were protected from $O A$ with in fact a significant enhancement of the OA score of the K63R mice (Fig. 3A and B). However, the medial femoral condyles of the K48R mice showed a significant reduction in the OA score compared to either 'wild-type' animals or 'wild-type' Ub transgenic animals (Fig. $3 \mathrm{~A}$ and B). Overall summation of the histological scores from both medial plateaus revealed no significant differences between transgenic and 'wild-type' animals (Fig. 3B).

\section{TRAFD1 positively regulates induced MMP13 expression}

Many components of signalling pathways are known to be modulated by Ub conjugation. Therefore we attempted to identify novel proteins ubiquitinated under either basal or stimulated conditions which may be important OA given our mouse-model findings, using chondrosarcoma SW1353 cell extracts. Ubiquitinated proteins were first enriched using TUBEs which have a nanomolar binding affinity for poly-ubiquitinated proteins.[9] After confirmation of the enrichment of Ub conjugated proteins (Fig. 4A, mid-panel), proteins were identified by MS using spectral counts to quantify relative abundance. We identified 176 proteins in total and the protein with the highest emPAI (exponentially modified protein abundance index) was ubiquitin in all samples (Supplementary table). Identified proteins with a reported role in NF- $\kappa$ B signalling are listed (Table 1). Of these, TRAFD1 was identified only under basal conditions and has been identified as a negative regulator of cytokine 
Running head: ubiquitination in osteoarthritis

signalling.[23] We therefore confirmed the association of TRAFD1 with ubiquitin by overexpression and immunoprecipitation of the protein followed by immunoblotting with antiUb antibody (Fig. 4B). Using RNAi we specifically depleted TRAFD1 from SW1353 cells (Fig. 4C) and measured IL-1- or poly(I-C)-induced gene expression. Depletion of TRAFD1 reduced both basal and induced expression of MMP13 (Fig. 4D). Previous work with TRAFD1 had focussed on IL6 regulation, again similar to our findings with MMP13, we observed a reduction in induced IL6 expression following TRAFD1 depletion (Fig. 4E). 
Running head: ubiquitination in osteoarthritis

\section{DISCUSSION}

To our knowledge this is the first detailed study to evaluate the therapeutic potential of inhibition of the UPS system for OA.

MG132 is a peptide aldehyde which directly inhibits the active site within the 20S core particle, the catalytic sub-complex of the $26 \mathrm{~S}$ proteasome. Using the DMM OA model we observed that 8-weeks post surgery, MG132-administered mice had a significant protection against OA-like cartilage erosions. Similarly, using a well established bovine ex vivo model of cartilage destruction, mediated by pro-inflammatory cytokines,[13] MG132 totally blocked resorption. Proteasomal inhibitors are considered as potential remedies for autoimmune and inflammatory diseases, including rheumatoid arthritis (RA) and have shown efficacy in animal models, including in rat models of OA. $[15,24,25]$ This is principally via their ability to inhibit NF- $\kappa B$ activation.[5] Thus, it was perhaps not surprising that here MG132 prevented cartilage destruction in our explant model, presumably via limiting $I \kappa B \alpha$ degradation, NF- $\kappa B$ signal transduction and MMP13 expression, all of which we demonstrated in vitro.

The NF- $\kappa B$ pathway inhibitor I $\kappa B$ was the first identified substrate of the UPS,[26] where following its K48 poly-ubiquitination it is degraded by the proteasome. In fact, multiple different Ub-conjugated proteins are involved in NF-אB signalling. For example, linear polyubiquitination of NEMO, K63 poly-ubiquitination of TRAF6 (itself the responsible E3 ligase), and K11 poly-ubiquitination of RIP1, all regulate the NF-KB pathway.[20] Similarly, deubiquitination plays an important role in NF- $\kappa B$ signalling, exemplified by A20.[27]

Although MG132 is a proteasome inhibitor it disrupts the entire UPS, leading to an accumulation of K48 poly-ubiquitination protein and a lack of bioavailable mono-Ub. In an attempt to resolve the mode of action of MG132 in the protection of DMM-induced OA we used 'wild-type', K48R and K63R Ub transgenic mice in further DMM studies. We observed that the K63R mice developed modestly, but significantly, worse OA. K63 poly-Ub chains are involved in range of cellular processes including intracellular trafficking and autophagy where their formation causes proteins to accumulate to the aggresome.[28] Autophagy is protective for healthy cartilage, where loss of the process is associated with cell death and OA-onset.[29] We therefore speculate that the K63R mice would have reduced autophagy, explaining the observed increase in OA score. Our data also indicates that linear poly- 
Running head: ubiquitination in osteoarthritis

ubiquitination has little importance in DMM-induced OA since all three transgenic Ub mice are incapable of this form of conjugation with their respective Ub-transgene. Somewhat pheno-copying the MG132 data, K48R transgenic animals showed significant protection from DMM-OA, but only on the less affected medial-femoral condyle, suggestive of a delay in OA-onset. These data warrant further investigation into the role of K48 polyubiquitination at earlier time points during DMM where lesions on the tibial plateau are initiating. A limitation of these studies is that all the transgenic mice are still able to make all poly-Ub conjugates because they still express the four copies of the endogenous $\mathrm{Ub}$ genes, UBA52, RPS27A, UBB and UBC,[30] although data suggest the transgenic mutant Ub acts as a dominant negative form.[18] A further limitation is that the transgenic animals were maintained on $\mathrm{FVB} / \mathrm{N}$ genetic background, rather than $\mathrm{C} 57 \mathrm{BI} / 6$, although we still observed reduced OA in K48R mice compared to the WT-Ub transgenics or 'WT' $\mathrm{C} 57 \mathrm{BI} / 6$ mice, which themselves developed OA indistinguishable from each other (Fig 3).

Given the protection mediated by both MG132 and the K48R Ub transgene the data indicate a role for the $26 \mathrm{~S}$ proteasome and potentially NF-KB signalling in DMM-OA. NF- $\kappa B$ signalling is the major inflammatory pathway but has yet to be investigated in DMM-induced OA, although the pathway has been extensively studied in chondrocytes and its inhibition can suppress $O A$ in an experimental model.[31] In fact the role of inflammation, and in particular IL-1, in OA remains controversial.[32] Importantly, although we used proinflammatory cytokines to study NF-KB activation and MMP13 expression, inflammatory signalling pathways, including NF- $\kappa B$, can be activated by other signals including mechanotransduction.[33] Chondrocytes are well known to respond to biomechanical signals to maintain cartilage homeostasis. The magnitude of these signals are critical for the control of the activation or inhibition of pro-inflammatory genes, even in the absence of classical inflammatory stimuli. Further, DMM-induced OA is mechanosensitive with several proinflammatory genes that activate $N F-\kappa B$, including $I L 1 b$ and $I L 6$, induced early following surgery and suppressed by joint immobilisation [34] - adding validity to our use of cytokines in vitro and our emphasis on NF-KB signalling. However, a number of other signalling pathways important for cartilage development and integrity are regulated by the UPS including TGF- $\beta$ and Wnt signalling. $[35,36]$ Our data cannot preclude that MG132 or the 
Running head: ubiquitination in osteoarthritis

K48R Ub-transgene may be affecting these or other pathways to reduce the cartilage damage induced following DMM surgery.

Given that multiple signalling pathways converge on the upregulation of aggrecanases and collagenases, especially MMP13, we sought to identify potentially novel Ub involved in such pathways using a novel proteomic method. From these proteomic data we identified TRAFD1, although we were unable to verify that the protein was directly ubiquitinated since the identified peptide lacked a characteristic lysine-diglycine modification found after trypsin digestion of ubiquitinated peptides. However, TRAFD1 has been previously identified as being ubiquitinated in large-scale proteomic screens for Ub-modified proteins,[37-39] with K103, K129 and K485 of the human protein showing modification. Here, we overexpressed and immunoprecipitated a tagged version of TRADF1 and confirmed the coimmunoprecipitation of Ub, presumably conjugated to TRAFD1.

We chose TRAFD1, also known as FLN29, for further study based upon previous work linking the protein to toll-like receptor (TLR) and retinoic acid-inducible gene 1 (RIG-1)-like helicase (RLH) signalling, $[23,40]$ and thus NF- $\kappa B$ signalling. In these studies, contrary to our findings, TRAFD1 is reportedly a negative regulator of TLR and RLH signalling.[23] The discrepancies between our findings and those published could perhaps be explained by differences in the cells or species used but clearly warrant further investigation. TRAFD1 was also reportedly important for IRF-3 dimerisation,[23] a process important for poly(I-C)-induced MMP13 expression by chondrocytes.[8]

Finally, $\mathrm{Ub}$ is a member of a family of ubiquitin-like proteins which includes the Small Ubiquitin-related Modifiers (SUMO). SUMO has recently been linked to MMP13 expression and potentially RA.[41] Thus, further work into the role of ubiquitin-like proteins in the arthritides is required.

In summary, here we describe for the first time that disruption of the UPS system is able to partially protect from OA-like cartilage destruction in the DMM murine model. Using a proteomic screen we identified TRAFD1 as a potential novel Ub target in chondrocytes and demonstrate that the depletion of the gene reduces the inflammatory induction of the potent collagenase MMP13. Further work is required to determine whether the protection from OA observed here by inhibition of the UPS is via TRAFD1, inhibition of NF- $\kappa B$ signalling, or perhaps via modulation of other pathways such as Wnt or TGF- $\beta$ signalling. 
Running head: ubiquitination in osteoarthritis

\section{ACKNOWLEDGEMENTS}

We thank Dr Achim Treumann, Proteomics \& Bio Mass Spec Facility, Newcastle University, for assistance with the MS analysis. This work was supported by funding from by the JGW Patterson Foundation, Medical Research Council, Nuffield Foundation (Oliver Bird Rheumatism Programme) and the Newcastle University Hospitals Special Trustees, UK. The research was supported by the National Institute for Health Research (NIHR) Newcastle Biomedical Research Centre based at Newcastle upon Tyne Hospitals NHS Foundation Trust and Newcastle University. The views expressed are those of the authors and not necessarily those of the NHS, the NIHR or the Department of Health. 
Running head: ubiquitination in osteoarthritis

\section{REFERENCES}

1. Arden N, Nevitt MC. Osteoarthritis: epidemiology. Best Pract Res Clin Rheumatol. 2006 Feb;20(1):3-25.

2. Loeser R. Molecular mechanisms of cartilage destruction in osteoarthritis. Biochemical Journal. 2008;8(4):303-6.

3. Muir $\mathrm{H}$. The chondrocyte, architect of cartilage. Biomechanics, structure, function and molecular biology of cartilage matrix macromolecules. Bioessays. 1995 Dec;17(12):1039-48.

4. Glasson SS, Askew R, Sheppard B, Carito B, Blanchet T, Ma HL, et al. Deletion of active ADAMTS5 prevents cartilage degradation in a murine model of osteoarthritis. Nature. 2005 Mar 31;434(7033):644-8.

5. Chitra S, Nalini G, Rajasekhar G. The ubiquitin proteasome system and efficacy of proteasome inhibitors in diseases. International journal of rheumatic diseases. 2012 Jun;15(3):249-60.

6. Li W, Ye Y. Polyubiquitin chains: functions, structures, and mechanisms. Cell Mol Life Sci. 2008 Aug;65(15):2397-406.

7. Zhang Q, Hui W, Litherland GJ, Barter MJ, Davidson R, Darrah C, et al. Differential Toll-like receptor-dependent collagenase expression in chondrocytes. Ann Rheum Dis. 2008 Nov;67(11):1633-41.

8. Radwan M, Gavriilidis C, Robinson JH, Davidson R, Clark IM, Rowan AD, et al. Matrix metalloproteinase 13 expression in response to double-stranded RNA in human chondrocytes. Arthritis Rheum. 2013 May;65(5):1290-301.

9. Lopitz-Otsoa F, Rodriguez-Suarez E, Aillet F, Casado-Vela J, Lang V, Matthiesen R, et al. Integrative analysis of the ubiquitin proteome isolated using Tandem Ubiquitin Binding Entities (TUBEs). Journal of proteomics. 2012 Jun 6;75(10):2998-3014. 
Running head: ubiquitination in osteoarthritis

10. Ishihama Y, Oda Y, Tabata T, Sato T, Nagasu T, Rappsilber J, et al. Exponentially modified protein abundance index (emPAl) for estimation of absolute protein amount in proteomics by the number of sequenced peptides per protein. Mol Cell Proteomics. 2005 Sep;4(9):1265-72.

11. Barter MJ, Pybus L, Litherland GJ, Rowan AD, Clark IM, Edwards DR, et al. HDACmediated control of ERK- and PI3K-dependent TGF-beta-induced extracellular matrixregulating genes. Matrix Biol. 2010 Sep;29(7):602-12.

12. Barter MJ, Hui W, Lakey RL, Catterall JB, Cawston TE, Young DA. Lipophilic statins prevent matrix metalloproteinase-mediated cartilage collagen breakdown by inhibiting protein geranylgeranylation. Ann Rheum Dis. 2010 Dec;69(12):2189-98.

13. Hui W, Cawston TE. In vitro model of cartilage degradation. Methods Mol Biol. 2010;622:341-8.

14. Glasson SS, Blanchet TJ, Morris EA. The surgical destabilization of the medial meniscus (DMM) model of osteoarthritis in the 129/SvEv mouse. Osteoarthritis Cartilage. 2007 Sep;15(9):1061-9.

15. Ahmed AS, Li J, Ahmed M, Hua L, Yakovleva T, Ossipov MH, et al. Attenuation of pain and inflammation in adjuvant-induced arthritis by the proteasome inhibitor MG132. Arthritis Rheum. 2010 Jul;62(7):2160-9.

16. Glasson SS, Chambers MG, Van Den Berg WB, Little CB. The OARSI histopathology initiative - recommendations for histological assessments of osteoarthritis in the mouse. Osteoarthritis Cartilage. 2010 Oct;18 Suppl 3:S17-23.

17. Culley KL, Hui W, Barter MJ, Davidson RK, Swingler TE, Destrument AP, et al. Class I histone deacetylase inhibition modulates metalloproteinase expression and blocks cytokineinduced cartilage degradation. Arthritis Rheum. 2013 Jul;65(7):1822-30. 
Running head: ubiquitination in osteoarthritis

18. Zhang $M$, Thurig S, Tsirigotis $M$, Wong PK, Reuhl KR, Gray DA. Effects of mutant ubiquitin on ts1 retrovirus-mediated neuropathology. Journal of virology. 2003 Jul;77(13):7193-201.

19. Tsirigotis M, Thurig S, Dube M, Vanderhyden BC, Zhang M, Gray DA. Analysis of ubiquitination in vivo using a transgenic mouse model. Biotechniques. 2001 Jul;31(1):120-6, 8,30 .

20. Iwai K. Diverse ubiquitin signaling in NF-kappaB activation. Trends in cell biology. 2012 Jul;22(7):355-64.

21. Buss H, Dorrie A, Schmitz ML, Hoffmann E, Resch K, Kracht M. Constitutive and interleukin-1-inducible phosphorylation of p65 NF-\{kappa\}B at serine 536 is mediated by multiple protein kinases including I\{kappa\}B kinase (IKK)-\{alpha\}, IKK\{beta\}, IKK\{epsilon\}, TRAF family member-associated (TANK)-binding kinase 1 (TBK1), and an unknown kinase and couples p65 to TATA-binding protein-associated factor II31-mediated interleukin-8 transcription. The Journal of biological chemistry. 2004 Dec 31;279(53):55633-43.

22. Xu J, Wang S, Zhang M, Wang Q, Asfa S, Zou MH. Tyrosine nitration of PA700 links proteasome activation to endothelial dysfunction in mouse models with cardiovascular risk factors. PloS one. 2012;7(1):e29649.

23. Sanada T, Takaesu G, Mashima R, Yoshida R, Kobayashi T, Yoshimura A. FLN29 deficiency reveals its negative regulatory role in the Toll-like receptor (TLR) and retinoic acid-inducible gene I (RIG-I)-like helicase signaling pathway. The Journal of biological chemistry. 2008 Dec 5;283(49):33858-64.

24. Yannaki E, Papadopoulou A, Athanasiou E, Kaloyannidis P, Paraskeva A, Bougiouklis $D$, et al. The proteasome inhibitor bortezomib drastically affects inflammation and bone disease in adjuvant-induced arthritis in rats. Arthritis Rheum. 2010 Nov;62(11):3277-88. 
Running head: ubiquitination in osteoarthritis

25. Quan R, Huang Z, Yue Z, Xin D, Yang D, Pan J, et al. Effects of a proteasome inhibitor on the NF-kappaB signalling pathway in experimental osteoarthritis. Scandinavian journal of rheumatology. 2013;42(5):400-7.

26. Palombella VJ, Rando OJ, Goldberg AL, Maniatis T. The ubiquitin-proteasome pathway is required for processing the NF-kappa B1 precursor protein and the activation of NF-kappa B. Cell. 1994 Sep 9;78(5):773-85.

27. Harhaj EW, Dixit VM. Regulation of NF-kappaB by deubiquitinases. Immunological reviews. 2012 Mar;246(1):107-24.

28. Yao TP. The role of ubiquitin in autophagy-dependent protein aggregate processing. Genes \& cancer. 2010 Jul 1;1(7):779-86.

29. Carames B, Taniguchi N, Otsuki S, Blanco FJ, Lotz M. Autophagy is a protective mechanism in normal cartilage, and its aging-related loss is linked with cell death and osteoarthritis. Arthritis Rheum. 2010 Mar;62(3):791-801.

30. Kimura Y, Tanaka K. Regulatory mechanisms involved in the control of ubiquitin homeostasis. Journal of biochemistry. 2010 Jun;147(6):793-8.

31. Chen LX, Lin L, Wang HJ, Wei XL, Fu X, Zhang JY, et al. Suppression of early experimental osteoarthritis by in vivo delivery of the adenoviral vector-mediated NFkappaBp65-specific siRNA. Osteoarthritis Cartilage. 2008 Feb;16(2):174-84.

32. Goldring MB, Otero M. Inflammation in osteoarthritis. Curr Opin Rheumatol. 2011 Sep;23(5):471-8.

33. Nam J, Aguda BD, Rath B, Agarwal S. Biomechanical thresholds regulate inflammation through the NF-kappaB pathway: experiments and modeling. PloS one. 2009;4(4):e5262. 
Running head: ubiquitination in osteoarthritis

34. Burleigh A, Chanalaris A, Gardiner MD, Driscoll C, Boruc O, Saklatvala J, et al. Joint immobilization prevents murine osteoarthritis and reveals the highly mechanosensitive nature of protease expression in vivo. Arthritis Rheum. 2012 Jul;64(7):2278-88.

35. van der Kraan PM, Goumans MJ, Blaney Davidson E, ten Dijke P. Age-dependent alteration of TGF-beta signalling in osteoarthritis. Cell Tissue Res. 2012 Jan;347(1):257-65.

36. Staines KA, Macrae VE, Farquharson C. Cartilage development and degeneration: a Wnt Wnt situation. Cell Biochem Funct. 2012 Dec;30(8):633-42.

37. Kim W, Bennett EJ, Huttlin EL, Guo A, Li J, Possemato A, et al. Systematic and quantitative assessment of the ubiquitin-modified proteome. Mol Cell. 2011 Oct 21;44(2):325-40.

38. Wagner SA, Beli P, Weinert BT, Scholz C, Kelstrup CD, Young C, et al. Proteomic analyses reveal divergent ubiquitylation site patterns in murine tissues. Mol Cell Proteomics. 2012 Dec;11(12):1578-85.

39. Hornbeck PV, Kornhauser JM, Tkachev S, Zhang B, Skrzypek E, Murray B, et al. PhosphoSitePlus: a comprehensive resource for investigating the structure and function of experimentally determined post-translational modifications in man and mouse. Nucleic Acids Res. 2012 Jan;40(Database issue):D261-70.

40. Mashima R, Saeki K, Aki D, Minoda Y, Takaki H, Sanada T, et al. FLN29, a novel interferon- and LPS-inducible gene acting as a negative regulator of toll-like receptor signaling. The Journal of biological chemistry. 2005 Dec 16;280(50):41289-97.

41. Frank S, Peters MA, Wehmeyer C, Strietholt S, Koers-Wunrau C, Bertrand J, et al. Regulation of matrixmetalloproteinase- 3 and matrixmetalloproteinase- 13 by SUMO-2/3 through the transcription factor NF-kappaB. Ann Rheum Dis. 2013 Nov 1;72(11):1874-81. 
Running head: ubiquitination in osteoarthritis

Table 1. TUBE-enriched, Ub-associated protein with a role in NF-KB signalling

\begin{tabular}{|c|c|c|c|c|c|c|c|}
\hline $\begin{array}{c}\text { Protein } \\
\text { \# }\end{array}$ & $\begin{array}{c}\text { protein } \\
\text { accession }\end{array}$ & short name & protein description & & emPAl & & $\begin{array}{c}\text { uniprot } \\
\text { accession }\end{array}$ \\
\hline & & - & & unst & IL-1 & plC & \\
\hline 1 & IPI00100154 & TOLLIP & Toll-interacting protein & 0.1 & 0.1 & 0.1 & Q9H0E2 \\
\hline 2 & IPI00009146 & TRAFD1 & TRAF-type zinc finger domain-containing protein 1 & 0.05 & ---- & ---- & 014545 \\
\hline 3 & IPI00094740 & RNF31 & Isoform 1 of RING finger protein 31 & ----- & 0.05 & ---- & Q96EP0 \\
\hline 4 & IPI00000816 & YWHAE & Isoform 1 of $14-3-3$ protein epsilon & ----- & 0.23 & 0.11 & P62258 \\
\hline 5 & IPI00021263 & YWHAZ & 14-3-3 protein zeta/delta & 0.38 & ---- & ---- & P63104 \\
\hline 6 & IPI00220740 & NPM1 & Isoform 2 of Nucleophosmin & ----- & ----- & 0.5 & P06748 \\
\hline 7 & IPI00179473 & SQSTM1 & Isoform 1 of Sequestosome-1 & 0.65 & 0.65 & 0.29 & Q13501 \\
\hline 8 & IPI00299147 & SUMO3 & Small ubiquitin-related modifier 3 & 1.1 & 0.64 & 0.64 & P55854 \\
\hline
\end{tabular}

* emPAI, Exponentially modified protein abundance index.[10] 
Running head: ubiquitination in osteoarthritis

\section{Figure legends}

Figure 1. UPS inhibition prevents cartilage destruction via blockade of NF- $\kappa B$ signaling to MMP13. (A) and (B). Bovine nasal cartilage was cultured in serum-free medium in the presence of either medium, or medium plus IL-1 and OSM both \pm MG132 or DMSO vehicle as described for 14 days. (A) Glycosaminoglycan (GAG) release into the medium was assayed using the dimethylmethylene blue assay [13] and is shown for day 7. (B). The levels of collagen fragments released into the medium were determined by measurement of hydroxyproline (OHPro).[13] Results shown are for the cumulative collagen release at day 14 of culture and expressed as a percentage of the total (mean \pm SD). Experiments were performed with three bovine noses with each experiment performed in quadruplicate. (C). Treatment toxicity was measured in condition medium (day 7 and 14 - presented) using the ToxiLight $^{\mathrm{TM}}$ BioAssay Kit. Data is average $(n=4)$ emitted light from a single bovine cartilage experiment with freeze-thawed cartilage used as a positive control and set to $100 \%$ toxicity. (D). SW1353 cells or HAC were stimulated with ligands $(\mathrm{pIC}=$ poly(I-C)) \pm MG132 or DMSO vehicle, as described and labelled, for $6 \mathrm{~h}$ or $24 \mathrm{~h}$ respectively. MMP13 and 185 expression were measured using real-time RT-PCR. (E). SW1353 cell were stimulated as described for $15 \mathrm{~min}$ and isolated protein subjected to immunoblotting with the indicated antibodies. GAPDH was used as a loading control. Real-time PCR results are combined data from 3 separate experiments ( $n=4$ /experiment) or representative of two patient HAC. Immunoblotting is representative of two experiments.

Figure 2. MG132 reduces cartilage destruction in the 'destabilisation of the medial meniscus' model in vivo. (A). OA in C57BL/6J mice was induced following surgical destabilization of the medial meniscus (DMM) as described. MG132 (1 mg/kg/day) or vehicle (DMSO/PEG) were delivered via subcutaneously implanted osmotic pump, with pumps replacement after 4 weeks. Data are shown at 8 weeks. Frontal sections $(5 \mu \mathrm{m})$ were stained with haematoxylin, safranin-O/fast green. Sections shown are representative of the most affected from a selected mouse (DMSO vehicle or MG132) and show the medial compartment of the knee joint ( $5 \times$ magnification). (B). Approximately fourteen sections from each mouse were graded by two blinded scorers using a validated scoring system.[16] The means of the highest score for each animal are plotted ( $n=8$ per group) for the medial 
Running head: ubiquitination in osteoarthritis

femoral condyle and tibial plateau and summation of both, with closed circles and open squares for vehicle or MG312 treated animals respectively. Line represents mean and error bars are SEM. Statistical significance was calculated using a Mann Whitney $U$ test.

Figure 3. Transgenic mutated ubiquitins differentially affect DMM-induced OA. (A). OA was induced in 10-week old mice transgenic for wild-type ubiquitin, K48R or K63R mutant ubiquitin on the FVB/N genetic background. After 8 weeks animals were sacrificed and knee frontal sections $(5 \mu \mathrm{m})$ stained with haematoxylin, safranin-O/fast green. Sections shown are representative of the most affected from a selected mouse for each genotype and show the medial compartment of the knee joint ( $5 \times$ magnification). (B). Approximately fourteen sections from each mouse were graded by two blinded scorers using a validated scoring system.[16] The means of the highest score for each animal are plotted for the medial femoral condyle and tibial plateau and summation of both. C57BL/6J mice $(n=22)$ from parallel surgery, by the same surgeon, were used to determine the effect transgenic 'wildtype' Ub. Line represents mean and error bars are SEM. Statistical significance was calculated using a Mann Whitney $U$ test.

Figure 4. TRAFD1 is a novel ubiquitinated substrate involved in inflammatory signalling. (A). Protein extracts from SW1353 cells were enriched for poly-ubiqtuinated substrates using TUBEs as described, with colloidal coomassie staining (upper-panel) and immunoblotting with an anti-Ub (Ub; mid-panel) antibody used to verify enrichment. Enriched ubiquitin-conjugated proteins were subjected to MS. $n-b$ is 'non-bound' protein collected after incubation with the TUBEs (B). SW1353 cells were transfected with a TRAFD1-FLAG construct or empty vector and overexpression confirmed by immunoblotting. Transfected cells were stimulated as indicated and FLAG-tagged proteins enriched by FLAGimmunoprecipitation, which was confirmed by FLAG-immunoblotting. (C). SW1353 cells were transfected with the indicated siRNA and TRAFD1 depletion confirmed by real-time RTPCR. (D) and (E) SW1353 cells were transfected with the indicated siRNA, stimulated with IL-1 (solid bars) or poly(I-C)(pIC) (shaded bars) as indicated for 6 or $24 \mathrm{~h}$, and MMP13 (D) or IL6 (E) expression measured by real-time RT-PCR. Data are shown as fold change relative to the cells transfected with a non-targeting siRNA (siCon). Real-time PCR data are from 3 separate experiments performed in quadruplicate. 

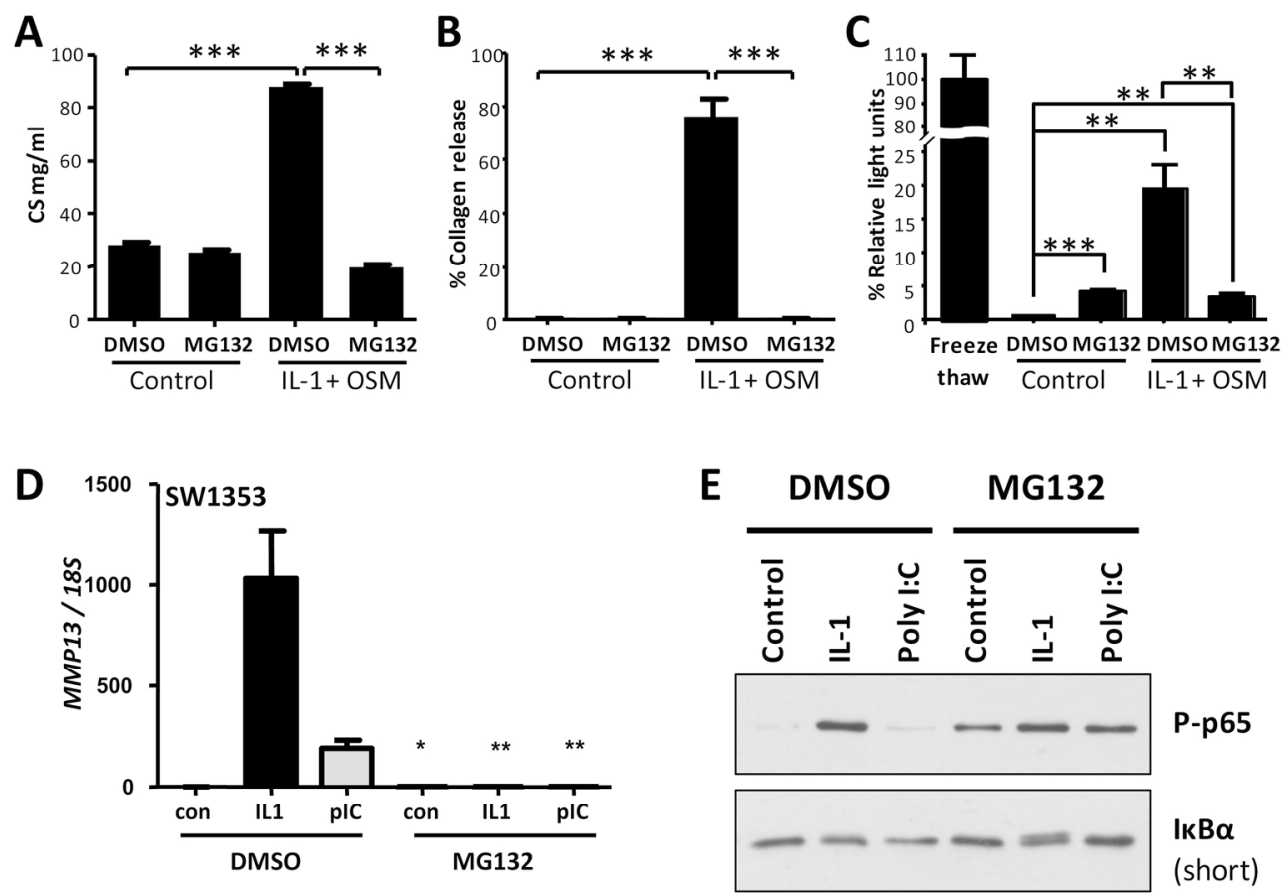

\section{P-p65}
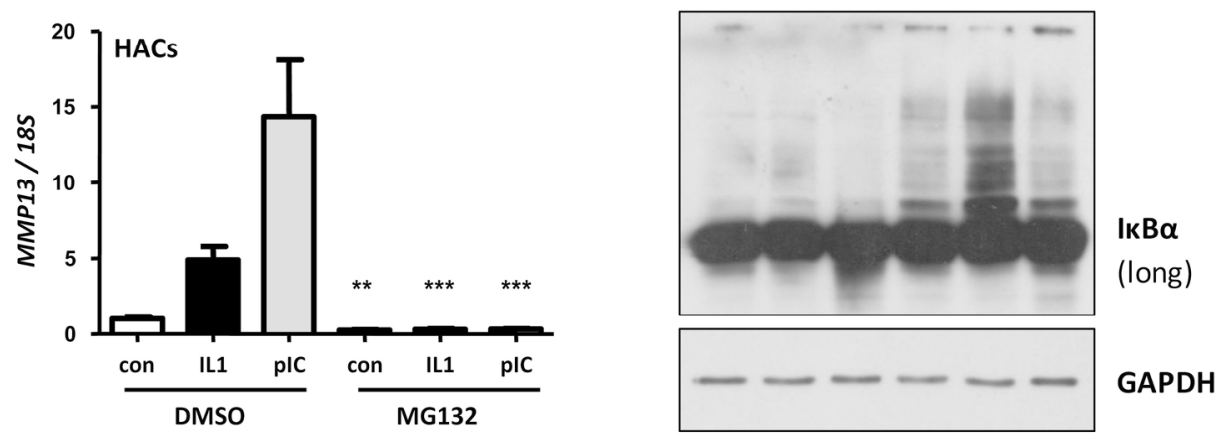

Figure 1. UPS inhibition prevents cartilage destruction via blockade of NF-kB signaling to MMP13. (A) and (B). Bovine nasal cartilage was cultured in serum-free medium in the presence of either medium, or medium plus IL-1 and OSM both \pm MG132 or DMSO vehicle as described for 14 days. (A) Glycosaminoglycan (GAG) release into the medium was assayed using the dimethylmethylene blue assay [13] and is shown for day 7.

(B). The levels of collagen fragments released into the medium were determined by measurement of hydroxyproline (OHPro).[13] Results shown are for the cumulative collagen release at day 14 of culture and expressed as a percentage of the total (mean \pm SD). Experiments were performed with three bovine noses with each experiment performed in quadruplicate. (C). Treatment toxicity was measured in condition medium (day 7 and 14 - presented) using the ToxiLight ${ }^{T M}$ BioAssay Kit. Data is average $(n=4)$ emitted light from a single bovine cartilage experiment with freeze-thawed cartilage used as a positive control and set to $100 \%$ toxicity. (D). SW1353 cells or HAC were stimulated with ligands (pIC $=$ poly(I-C)) \pm MG132 or DMSO vehicle, as described and labelled, for $6 \mathrm{~h}$ or $24 \mathrm{~h}$ respectively. MMP13 and $18 \mathrm{~S}$ expression were measured using real-time RT-PCR. (E). SW1353 cell were stimulated as described for $15 \mathrm{~min}$ and isolated protein subjected to immunoblotting with the indicated antibodies. GAPDH was used as a loading control. Real-time PCR results are combined data from 3 separate experiments ( $n=4$ /experiment) or representative of two patient HAC. Immunoblotting is representative of two experiments. $186 \times 192 \mathrm{~mm}(300 \times 300 \mathrm{DPI})$ 


\section{A}
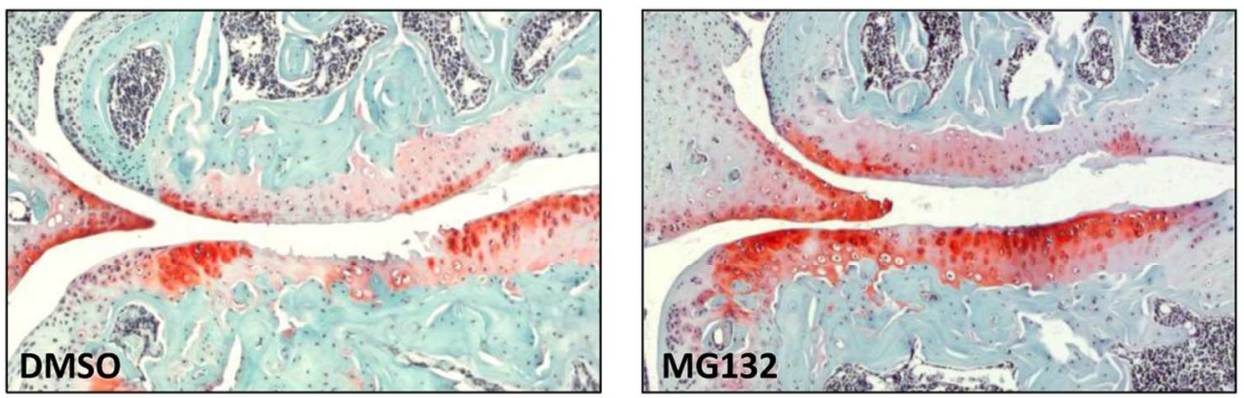

B

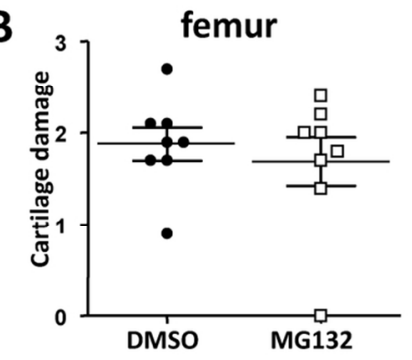

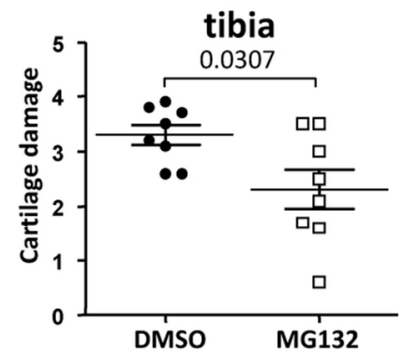

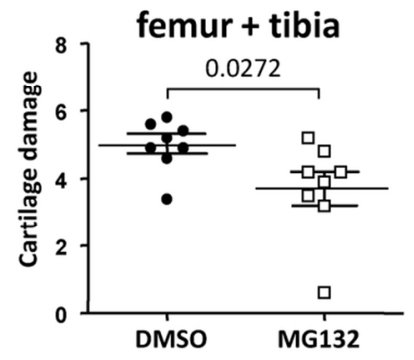

Figure 2. MG132 reduces cartilage destruction in the 'destabilisation of the medial meniscus' model in vivo. (A). OA in C57BL/6J mice was induced following surgical destabilization of the medial meniscus (DMM) as described. MG132 (1 mg/kg/day) or vehicle (DMSO/PEG) were delivered via subcutaneously implanted osmotic pump, with pumps replacement after 4 weeks. Data are shown at 8 weeks. Frontal sections $(5 \mu \mathrm{m})$ were stained with haematoxylin, safranin-O/fast green. Sections shown are representative of the most affected from a selected mouse (DMSO vehicle or MG132) and show the medial compartment of the knee joint ( $5 \times$ magnification). (B). Approximately fourteen sections from each mouse were graded by two blinded scorers using a validated scoring system.[16] The means of the highest score for each animal are plotted ( $n=8$ per group) for the medial femoral condyle and tibial plateau and summation of both, with closed circles and open squares for vehicle or MG312 treated animals respectively. Line represents mean and error bars are SEM. Statistical significance was calculated using a Mann Whitney $\mathrm{U}$ test. $101 \times 65 \mathrm{~mm}(300 \times 300 \mathrm{DPI})$ 

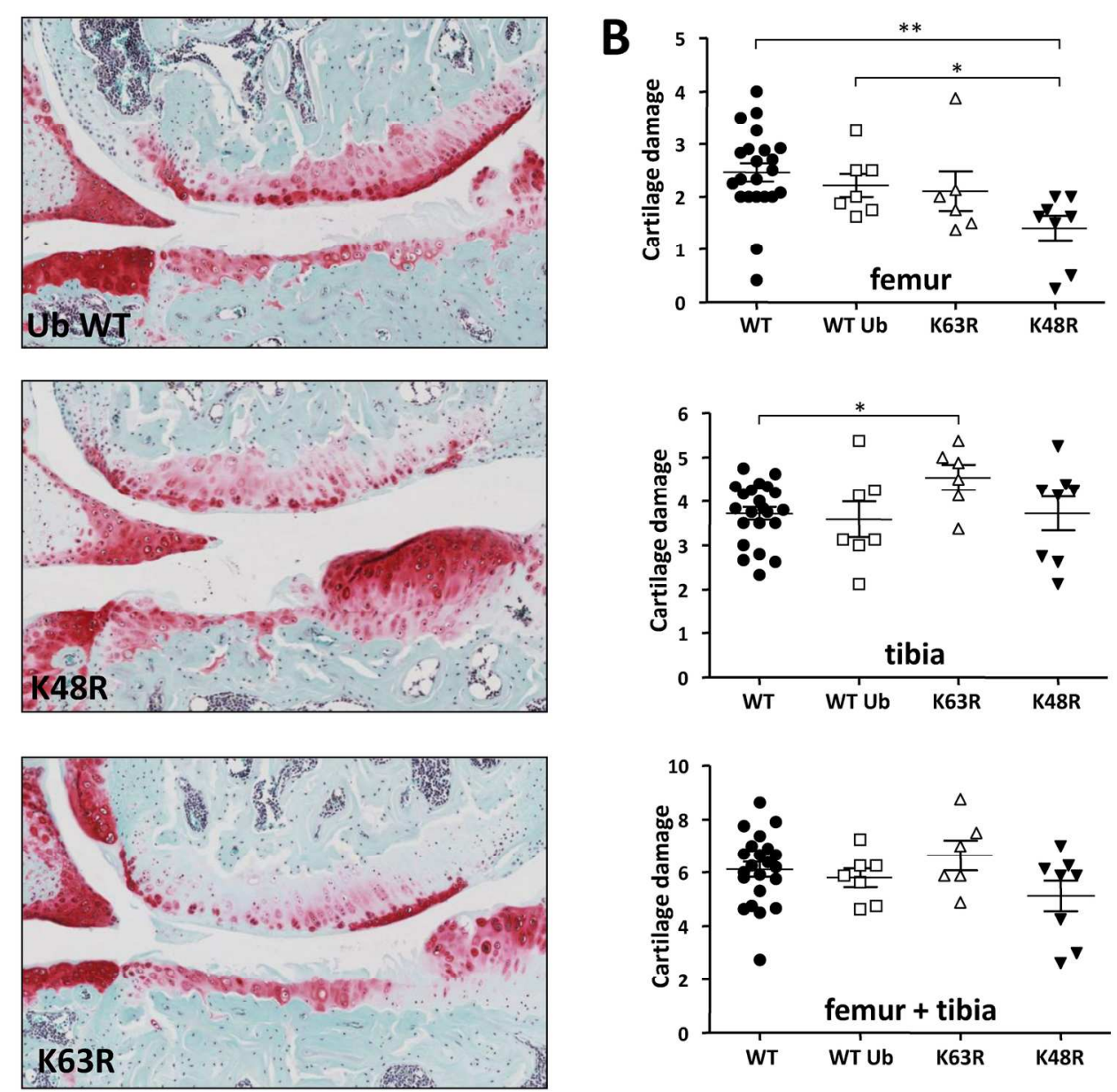
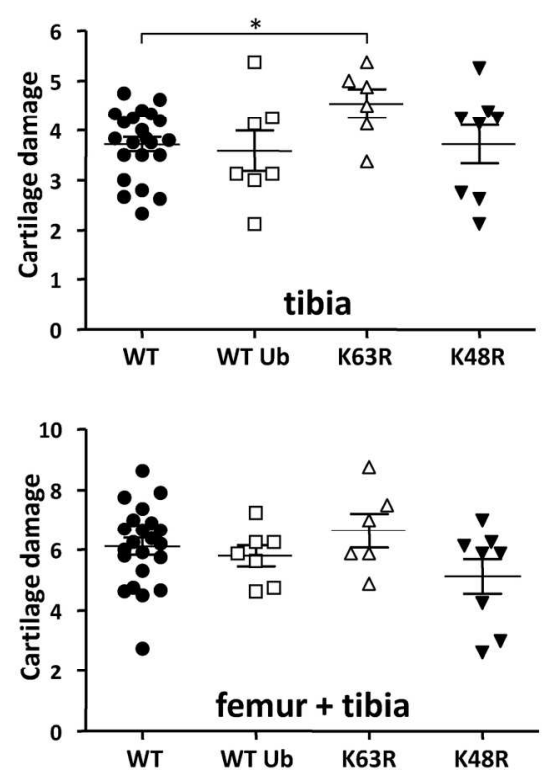

Figure 3. Transgenic mutated ubiquitins differentially affect DMM-induced OA. (A). OA was induced in 10week old mice transgenic for wild-type ubiquitin, K48R or K63R mutant ubiquitin on the FVB/N genetic

background. After 8 weeks animals were sacrificed and knee frontal sections $(5 \mu \mathrm{m})$ stained with haematoxylin, safranin-O/fast green. Sections shown are representative of the most affected from a selected mouse for each genotype and show the medial compartment of the knee joint ( $5 \times$ magnification). (B). Approximately fourteen sections from each mouse were graded by two blinded scorers using a validated scoring system.[16] The means of the highest score for each animal are plotted for the medial femoral condyle and tibial plateau and summation of both. C57BL/6J mice $(n=22)$ from parallel surgery, by the same surgeon, were used to determine the effect transgenic 'wild-type' Ub. Line represents mean and error bars are SEM. Statistical significance was calculated using a Mann Whitney $\mathrm{U}$ test. $166 \times 158 \mathrm{~mm}(300 \times 300 \mathrm{DPI})$ 
A input TUBES $n-b$

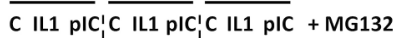

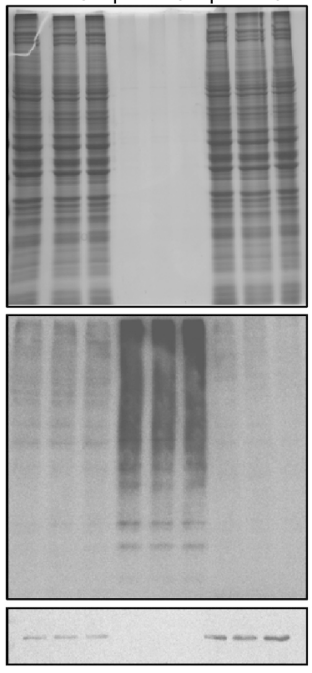

Collloidal coomassie IB: Ub

IB: GAPDH

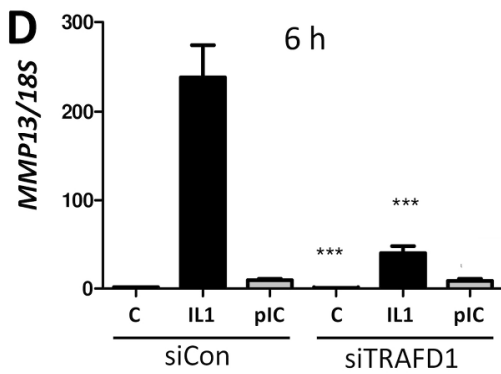

C
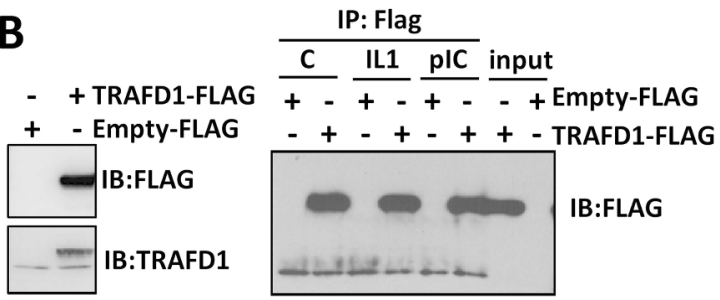

IB:FLAG IB:TRAFD1
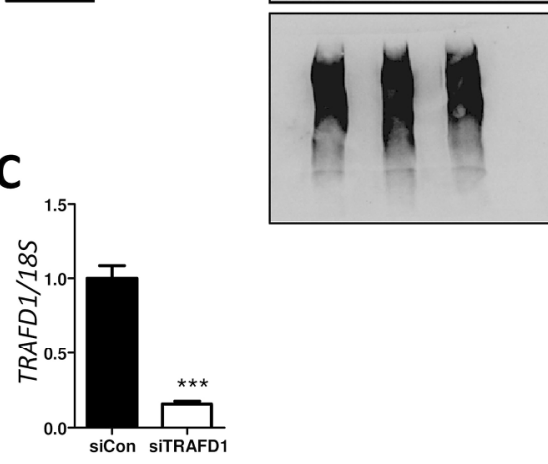

IB:Ub

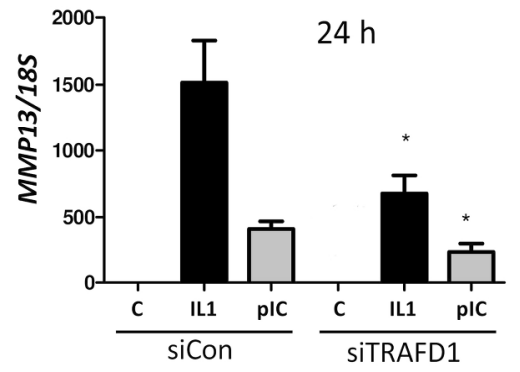

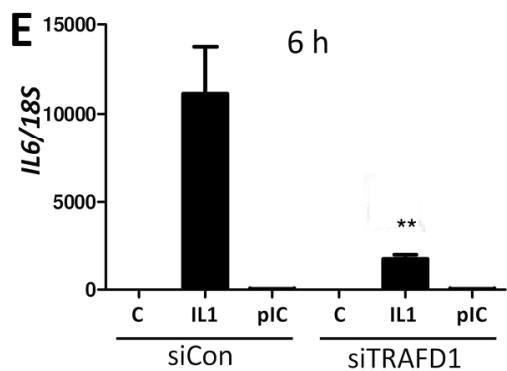

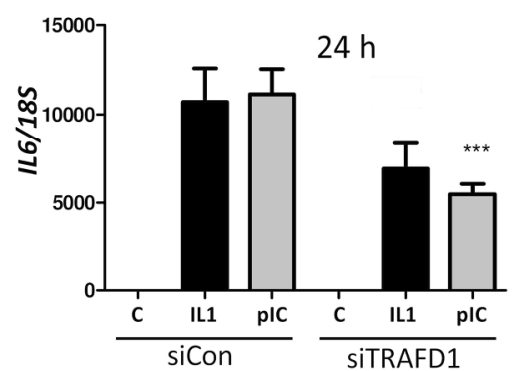

Figure 4. TRAFD1 is a novel ubiquitinated substrate involved in inflammatory signalling. (A). Protein extracts from SW1353 cells were enriched for poly-ubiqtuinated substrates using TUBEs as described, with colloidal coomassie staining (upper-panel) and immunoblotting with an anti-Ub (Ub; mid-panel) antibody used to verify enrichment. Enriched ubiquitin-conjugated proteins were subjected to MS. n-b is 'non-bound' protein collected after incubation with the TUBEs (B). SW1353 cells were transfected with a TRAFD1-FLAG construct or empty vector and overexpression confirmed by immunoblotting. Transfected cells were stimulated as indicated and FLAG-tagged proteins enriched by FLAG-immunoprecipitation, which was confirmed by FLAGimmunoblotting. (C). SW1353 cells were transfected with the indicated siRNA and TRAFD1 depletion confirmed by real-time RT-PCR. (D) and (E) SW1353 cells were transfected with the indicated SiRNA, stimulated with IL-1 (solid bars) or poly(I-C)(PIC) (shaded bars) as indicated for 6 or $24 \mathrm{~h}$, and MMP13 (D) or IL6 (E) expression measured by real-time RT-PCR. Data are shown as fold change relative to the cells transfected with a non-targeting siRNA (siCon). Real-time PCR data are from 3 separate experiments performed in quadruplicate. 


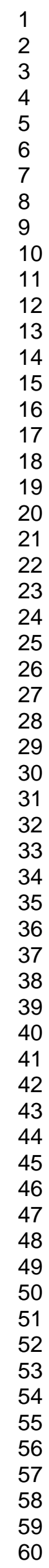

$218 \times 265 \mathrm{~mm}(300 \times 300 \mathrm{DPI})$

http://mc.manuscriptcentral.com/ard 

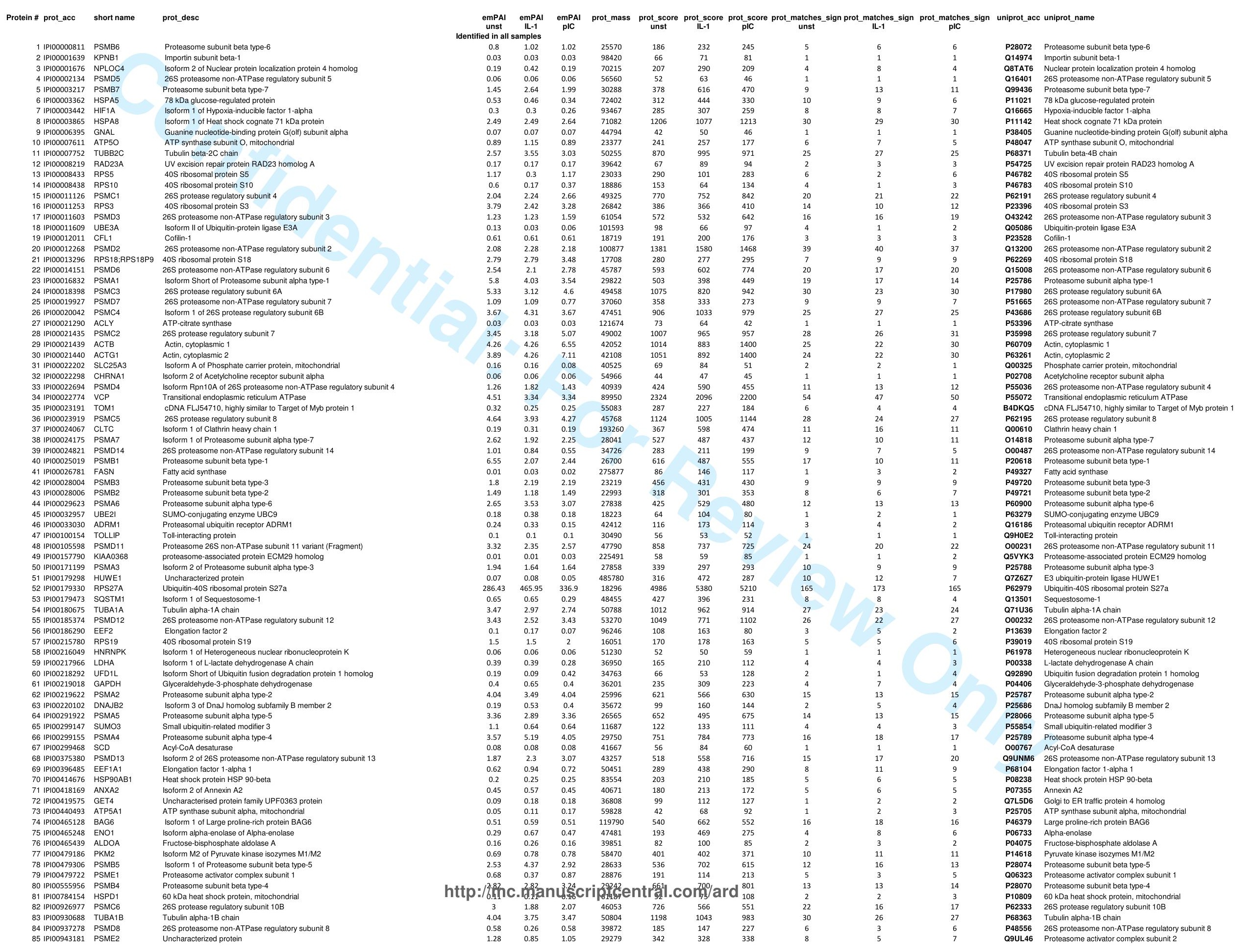

2
3
4
5
6
7
7
9
9
10
11
12
13
14
15
16
17
18
19
20
21
22
23
24

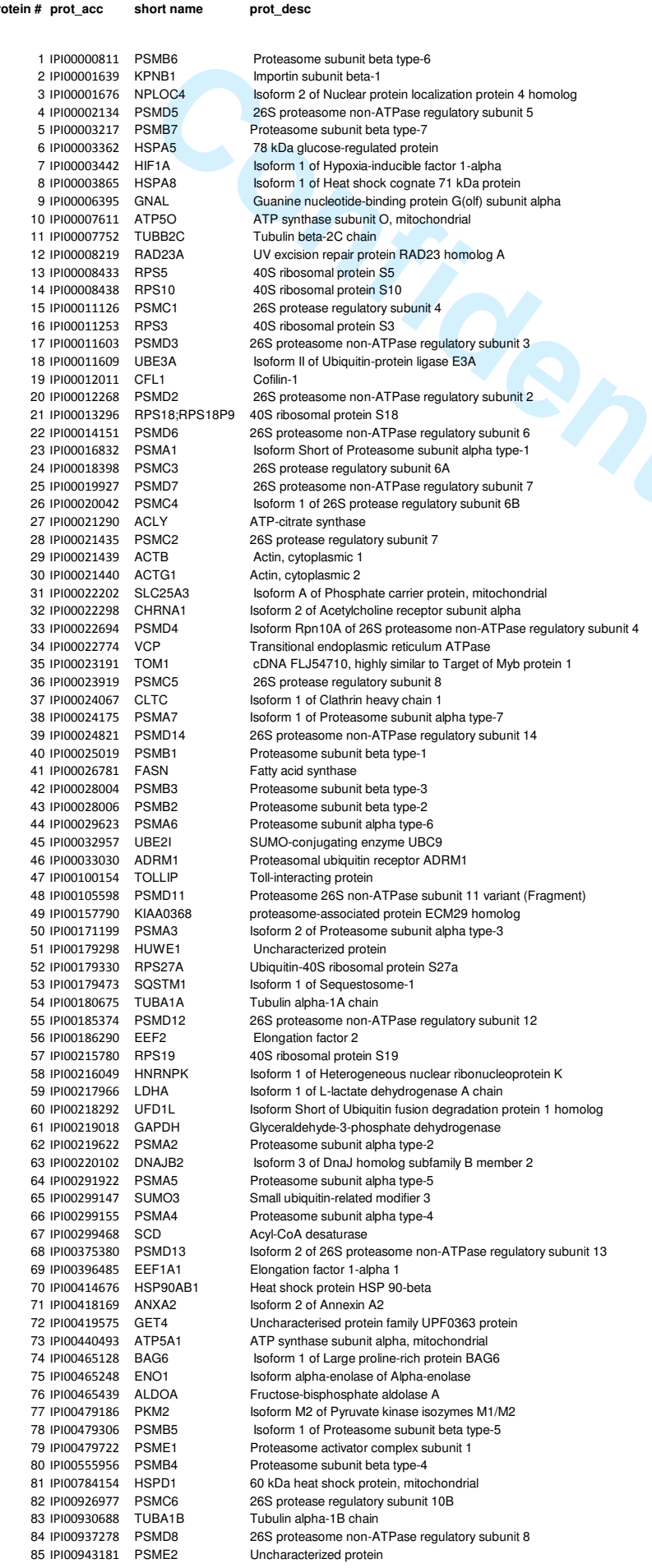

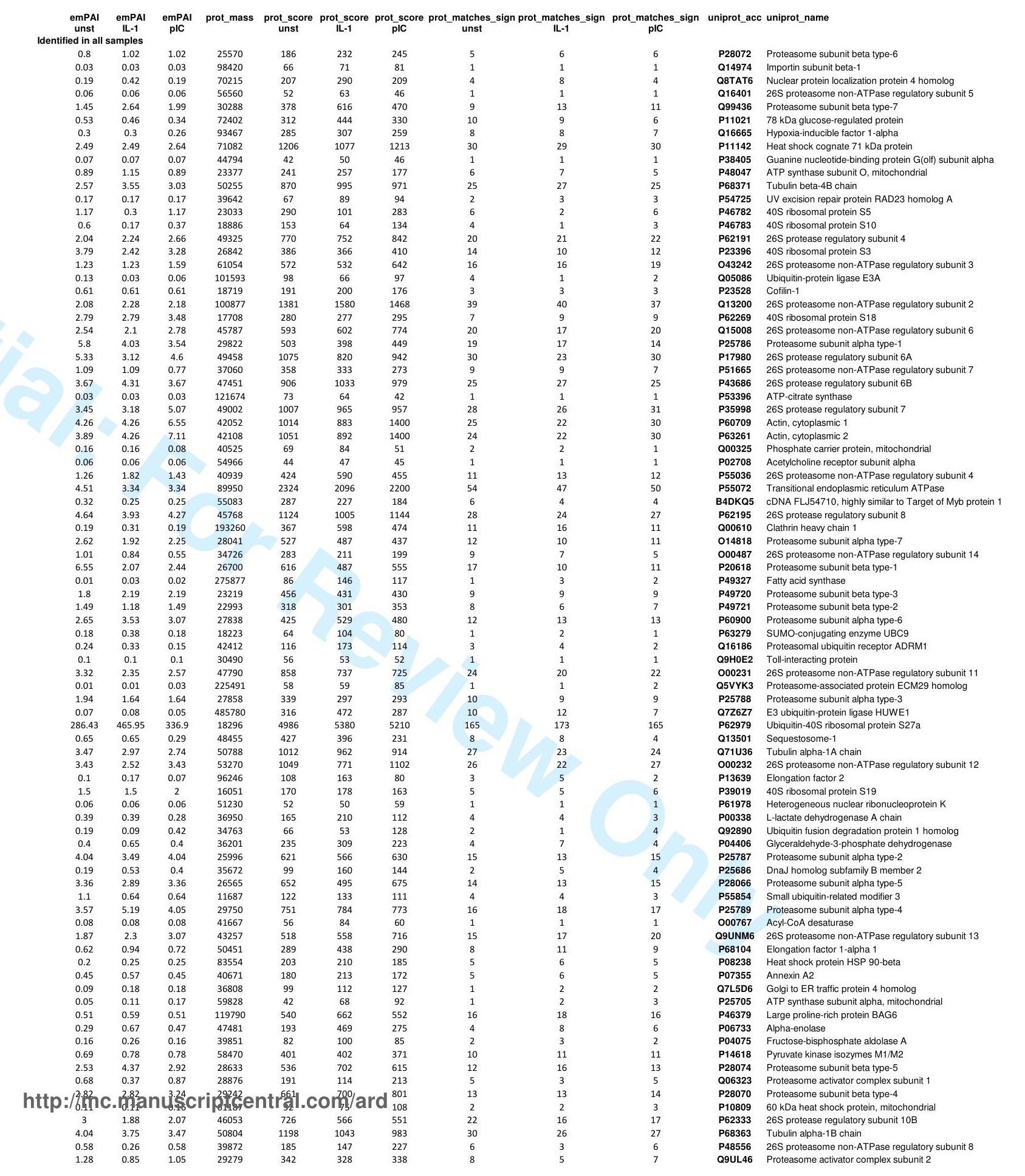




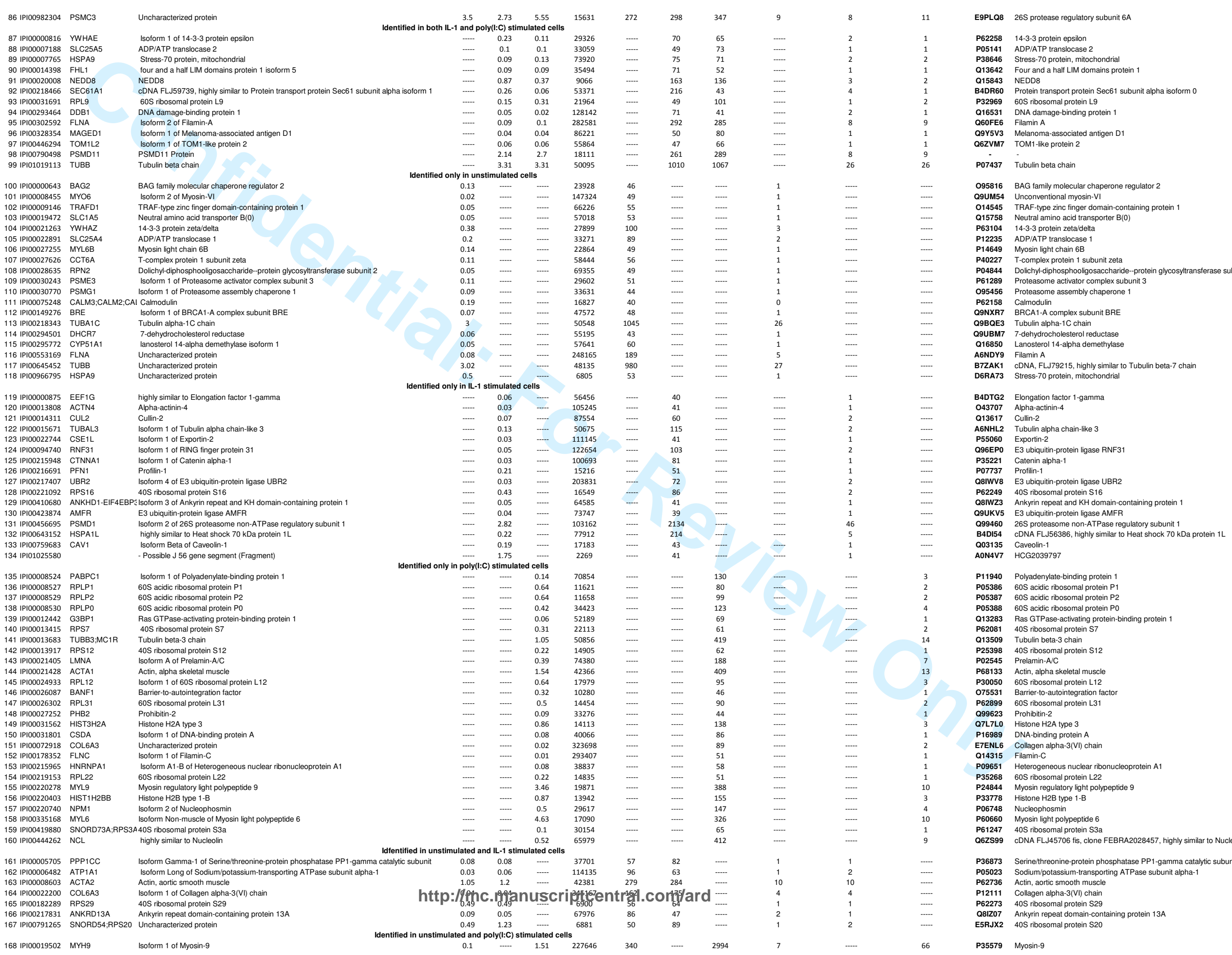




\section{Annals of the Rheumatic Diseases}

\begin{tabular}{|c|c|c|c|c|c|c|c|c|c|c|c|c|c|c|}
\hline 169 IP100026271 & RPS14 & 40 S ribosomal protein S14 & 0.2 & ...-.. & 0.43 & 16434 & 59 & $\ldots-.-$ & 93 & 1 & $\ldots-.-$ & 2 & P62263 & 40S ribosomal protein S14 \\
\hline 170 IP100033494 & MYL12B & Myosin regulatory light chain $12 B$ & 0.16 & $\ldots-.-$ & 5.99 & 19824 & 66 & $\ldots-$ & 584 & 1 & $\ldots-. .-$ & 13 & 014950 & Myosin regulatory light chain $12 B$ \\
\hline 171 IPI00299608 & PSMD1 & Isoform 1 of $26 \mathrm{~S}$ proteasome non-ATPase regulatory subunit 1 & 2.45 & $-\ldots-$ & 2.35 & 106795 & 1808 & $\ldots-$. & 1909 & 45 & $\ldots . .$. & 43 & 099460 & 26S proteasome non-ATPase regulatory subunit 1 \\
\hline 172 IPI00303476 & АТР5B & ATP synthase subunit beta, mitochondrial & 0.06 &.--- & 0.11 & 56525 & 49 & $\ldots--$ & 89 & 1 & $\ldots .$. & 2 & P06576 & ATP synthase subunit beta, mitochondrial \\
\hline 173 IPI00418471 & VIM & Vimentin & 0.25 & -..-- & 2.11 & 53676 & 100 & $\ldots--$ & 621 & 4 & $\ldots-$ & 20 & P08670 & Vimentin \\
\hline 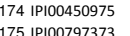 & $\begin{array}{l}\text { RPS16 } \\
\text { DOCK8 }\end{array}$ & $\begin{array}{l}\text { Uncharacterized protein } \\
\text { Is soform tof Dedicator of cytokinesis protein } 8\end{array}$ & 0.67 & $\cdots$ & 0.67 & $\begin{array}{l}17267 \\
240886\end{array}$ & ${ }_{53}^{102}$ & $\cdots$ & ${ }_{42}^{120}$ & 3 & $\cdots$ & 3 & $\begin{array}{l}\text { Q6IPX4 } \\
\text { O8NN50 }\end{array}$ & $\begin{array}{l}40 S \text { ribosomal protein S16 } \\
\text { Dedicator of cytokinesis rotein } 8\end{array}$ \\
\hline $\begin{array}{l}175 \text { III10007977373 } \\
176 \text { IP100968128 }\end{array}$ & $\begin{array}{l}\text { Dock8 } \\
\text { RPL9 }\end{array}$ & $\begin{array}{l}\text { Issoform } 1 \text { of Dedicator of cytokinesis protein } 8 \\
\text { Protoin }\end{array}$ & $\begin{array}{l}0.01 \\
0.15\end{array}$ & $\ldots-$. & 0.32 & 21671 & 45 & $\ldots$ & $\begin{array}{l}42 \\
81\end{array}$ & 1 & $\ldots .$. & $\frac{1}{2}$ & & \\
\hline
\end{tabular}

